\title{
ON THE SOLUTIONS FOR AN EXTENSIBLE BEAM EQUATION WITH INTERNAL DAMPING AND SOURCE TERMS
}

\section{Ducival C. Pereira, Hoang Nguyen, Carlos A. Raposo and Celsa H. M. MARANHÃO}

Abstract. In this manuscript, we consider the nonlinear beam equation with internal damping and source term

$$
u_{t t}+\Delta^{2} u+M\left(|\nabla u|^{2}\right)(-\Delta u)+u_{t}=|u|^{r-1} u
$$

where $r>1$ is a constant, $M(s)$ is a continuous function on $[0,+\infty)$. The global solutions are constructed by using the Faedo-Galerkin approximations, taking into account that the initial data is in appropriate set of stability created from the Nehari manifold. The asymptotic behavior is obtained by the Nakao method. 93D20.

Mathematics subject classification (2010): 35B40, 35G30, 35K30, 74K20, 74K10, 74Kxx, 93D15,

Keywords and phrases: Nonlinear beam equation, existence, uniqueness, asymptotic behavior, source term.

\section{REFERENCES}

[1] J. M. BALL, Initial boundary value problems for an extensible beam, J. Math. Anal. Appl., 42 (1973), $61-90$.

[2] J. M. BALL, Stability theory for an extensible beam, J. Differential Equations, 14 (1973), 399-418.

[3] P. BILER, Remark on the decay for damped string and beam equations, Nonlinear Anal., 10 (1986), 839-842.

[4] E. H. BRITO, Decay estimates for generalized damped extensible string and beam equations, Nonlinear Anal., 8 (1984), 1489-1496.

[5] R. W. DickeY, The initial value problem for a nonlinear semi-infinite string, Proc. Roy. Soc. Edinburgh A, 82 (1978), 19-26.

[6] L. A. Medeiros, On a new class of nonlinear wave equations, J. Math. Anal. Appl., 69 (1979), 252-262.

[7] D. C. PEREIRA, Existence, uniqueness and asymptotic behavior for solutions of the nonlinear beam equation, Nonlinear Anal., 8 (1990), 613-623.

[8] H. R. Clark, M. A. Rincon, R. D. Rodrigues, Beam equation with weak-internal damping in domain with moving boundary, Applied Numerical Mathematics, 47, 2 (2003), 139-157.

[9] D. C. Pereira, R. F. C. Lobato, C. A. Raposo, Energy decay to an abstract coupled system of extensible beams models, Appl. Math. Inf. Sci., 6, 3 2012, 447-452.

[10] M. Berger, A new approach to the large deflection of plate, J. Appl. Mech., 22 (1955), 465-472.

[11] C. A. RAposo, M. L. SANTOS, J. FerReIRA, Existence and uniform decay for a nonlinear beam equation with nonlinearity of Kirchhoff type in domains with moving boundary, Abstract and Applied Analysis, 8 (2005), 901-919.

[12] I. Chueshov, I. LASIECKA, Long-time behavior of second order evolution equations with nonlinear damping, Amer. Math. Soc., Mem. Amer. Math. Soc. 195, Providence, RI, 2008.

[13] S. WOINOWSKY-KRIEGER, The effect of an axial force on the vibration of hinged bars, Journal Applied Mechanics, 17 (1950), 35-36. 
[14] A. Ambrosetti, P. H. Rabinowitz, Dual variational methods in critical point theory and applications, J. Functional Analysis, 14 (1973), 349-381.

[15] M. Willem, Minimax Theorems, Progress in Nonlinear Differential Equations and their Applications 24, Birkhouser Boston Inc., Boston, MA, 1996.

[16] S. G. Miklin, Variational Methods in Mathematical Physics, Pergamon Press, Oxford, 1964.

[17] E. A. Coddington, N. Levinson, Theory of Ordinary Differential Equations, McGraw-Hill Inc., New York, 1955.

[18] J. K. Hale, Ordinary Differential Equations, 2nd ed., Dover Publications, INC, New York, 1997.

[19] J. L. Lions, Quelques méthodes de résolution des problèmes aux limites non linéaires, DunodGauthier Villars, Paris, 1969.

[20] M. NAKAO, Decay of solutions for some nonlinear evolution equations, J. Math. Analysis Appl., 60 (1977), 542-549.

[21] D. C. PEREIRA, Existence, uniqueness and asymptotic behavior for solutions of the nonlinear beam equation, Nonlinear Analysis, Theory, Methods \& Applications, 14, 8 (1990), 613-623.

[22] E. PIS KIN, Existence, decay and blow up of solutions for the extensible beam equation with nonlinear damping and source terms, Open Math., 13 (2015), 408-420.

[23] A. H. NAYFeh, D. T. Mook, Nonlinear Oscillations, Willy Interscience, New York, 1979.

[24] D. Burgreen, Free vibrations of a pin-ended column with constant distance between pin ends, J. Appl. Mech., 18 (1951), 135-139.

[25] J. G. EISLEY, Nonlinear vibration of beams and rectangular plates, Z. Angew. Math. Phys., 15 (1964), $167-175$.

[26] Y. YE, Global existence and asymptotic behavior of solutions for a class of nonlinear degenerate wave equations, Differ. Equ. Nonlinear Mech., 019685 (2007).

[27] L. BoCIU, I. LASIECKA, Uniqueness of weak solutions for the semilinear wave equations with supercritical boundary/interior sources and damping, Discrete Contin. Dyn. Syst., 22 (2008), 835-860.

[28] M. M. Cavalcanti, V. N. D. Cavalcanti, J. A. Soriano, Global existence and asymptotic stability for the nonlinear and generalized damped extensible plate equation, Commun. Contemp. Math., 6 (2004), 705-731.

[29] Y. ZHIJIAN, On an extensible beam equation with nonlinear damping and source terms, J. Differential Equations, 254 (2013), 3903-3927. 